\title{
Oea
}

JURNAL PENDIDIKAN GEOGRAFI

\section{PENGARUH LINGKUNGAN SEKOLAH TERHADAP KECERDASAN SPASIAL PESERTA DIDIK MELALUI AFFORDANCE DAN GEO- LITERACY MENGGUNAKAN ANALISIS JALUR (Studi Kasus SMA Negeri di Kota Bandung dan Kabupaten Bandung)}

\author{
Faiz Urfan \\ Program Studi Magister Pendidikan Geografi - Universitas Pendidikan Indonesia \\ faiz.urfan@student.upi.edu
}

\begin{abstract}
Spatial intelligence is an important component in Geography learning, because Geography is a discipline that studies about the space. The school environment has an influence on the increase in spatial intelligence of students. However, explanation about the mechanism of the influence of the school environment on spatial intelligence have not found until now. This is a survey research of the public high school in Bandung City and Bandung District with a total sample of 264 respondents in nine schools. The influence of the school environment on spatial intelligence can be explained by the path analysis involved in two other variables, that is affordance and geo-literacy. The conclusions of this research are (1) the school environment does not significantly affect the affordance; (2) the school environment and affordance significantly influence the geo-literacy; (3) affordance and geo-literacy significantly influence the spatial intelligence. Researchers recommend that the concept of spatial intelligence in learning geography should be assessed to generate a valid concept.
\end{abstract}

Keywords: School environment, affordance, geo-literacy, spatial intelligence, path analysis.

\begin{abstract}
ABSTRAK
Dalam pembelajaran Geografi, kecerdasan spasial merupakan komponen yang penting karena Geografi merupakan disiplin ilmu yang mempelajari tentang ruang (space). Lingkungan sekolah memiliki pengaruh terhadap peningkatan kecerdasan spasial peserta didik. Namun sampai saat ini belum ditemukan penjelasan yang spesifik tentang mekanisme pengaruh lingkungan sekolah terhadap kecerdasan spasial. Penelitian ini merupakan penelitian survei dan dilakukan di SMA negeri di Kota Bandung dan SMA negeri Kabupaten Bandung dengan jumlah sampel sebanyak 264 responden yang tersebar di sembilan sekolah. Pengaruh lingkungan sekolah terhadap kecerdasan spasial dapat dijelaskan dengan analisis jalur yang melibatkan dua variabel lain, yakni affordance dan geoliteracy. Adapun kesimpulan yang dihasilkan yaitu (1) lingkungan sekolah tidak signifikan berpengaruh terhadap affordance; (2) lingkungan sekolah dan affordance secara signifikan berpengaruh terhadap geo-literacy; (3) affordance dan geo-literacy secara signifikan berpengaruh terhadap kecerdasan spasial. Peneliti merekomendasikan agar konsep kecerdasan spasial dalam pembelajaran Geografi terus dikaji untuk melahirkan konsep yang valid dan baku.
\end{abstract}

Kata kunci: Lingkungan sekolah, affordance, geo-literacy, kecerdasan spasial, analisis jalur. 


\section{PENDAHULUAN}

Lingkungan sekolah memiliki peranan yang penting dalam keberhasilan belajar peserta didik. Menurut Oktaviana (2015, hlm. 19) "lingkungan sekolah turut mempengaruhi tingkat keberhasilan belajar siswa." Hal ini seharusnya disikapi secara serius oleh para pengelola sekolah. Namun fakta di lapangan menunjukkan bahwa sangat jarang pengelola atau penanggungjawab sekolah yang merancang lingkungan sekolah dengan dasar yang kuat untuk mencapai suatu tujuan. Seringkali lingkungan sekolah hanya dianggap sebagai faktor sampingan yang cukup dipenuhi dari segi kebersihan dan kelengkapannya. Padahal setiap elemen yang ada dalam lingkungan sekolah perlu diperhitungkan keberadaannya agar sinergis dengan tujuan pembelajaran di kelas. Hal tersebut perlu dilakukan agar usaha penataan lingkungan sekolah menjadi efektif sehingga menghasilkan lingkungan sekolah yang optimal dalam mendukung peningkatan kualitas akademik peserta didik. Hal ini sesuai dengan pernyataan Sudikno dan Aminah (2014, hlm. 48) yang menyatakan "keadaan lingkungan sekolah yang kondusif akan menciptakan ketenangan dan kenyamanan dalam belajar sehingga akan berjalan dengan baik mudah dalam menguasai materi pelajaran secara maksimal."

Salah satu aspek yang dipengaruhi oleh lingkungan sekolah terhadap peserta didik adalah kecerdasan spasial. Sutomo (2013, hlm. 40) menjelaskan bahwa "persepsi dan reaksi manusia terhadap peristiwa dan gejala geografis di sekitarnya akan terekam dalam benaknya menjadi pengetahuan terstruktursistematis." Kemudian Newcombe dan Frick (2010, hlm. 102) pun menyatakan bahwa "any mobile organism must be able to navigate in its world to survive and must represent the spatial environment in order to do so." Pernyataan tersebut menegaskan bahwa kecerdasan spasial memiliki keterkaitan yang erat dengan lingkungan. Tanpa kecerdasan spasial, manusia tidak akan mampu beradaptasi karena tidak mampu memposisikan dirinya di permukaan bumi serta tidak tahu harus bergerak ke mana untuk memenuhi kebutuhannya. Dalam kasus peserta didik, maka kecerdasan spasial dapat dikaitkan dengan kondisi lingkungan sekolah. Namun lingkungan sekolah tidak secara langsung mempengaruhi kecerdasan spasial. Ada faktor lain yang ada pada diri manusia yang lebih dekat kaitannya dengan lingkungan. Oleh karena itu, perlu dilibatkan faktor lain yang berkaitan.

Faktor yang diduga dapat menjelaskan pengaruh lingkungan sekolah terhadap kecerdasan spasial adalah affordance dan geo-literacy. Affordance merupakan persepsi manusia terhadap lingkungan sebagai media tempat dia beraktivitas. Sedangkan geoliteracy merupakan konsep yang menjelaskan tentang kemelekan seseorang untuk melihat berbagai peristiwa dan gejala di permukaan bumi dengan pendekatan Geografi. Uraian ini menjelaskan bahwa lingkungan sekolah memiliki pengaruh terhadap affordance, kemudian affordance berpengaruh terhadap geo-literacy. Sedangkan affordance dan geo-literacy akan berpengaruh terhadap kecerdasan spasial. Artikel ini bertujuan untuk menjelaskan bagaimana lingkungan sekolah berpengaruh terhadap kecerdasan spasial berdasarkan model tersebut. Setelah mengetahui mekanisme tersebut maka diharapkan para pembaca dapat merancang lingkungan sekolah secara efektif untuk meningkatkan kecerdasan spasial.

Kehidupan peserta didik tidak dapat terlepas dari lingkungan sekolahnya. Sebagai salah satu dari bagian kecerdasan, kecerdasan spasial pun dapat dipengaruhi oleh kondisi lingkungan. Kecerdasan yang didapatkan dari kondisi lingkungan disebut crystallized intelligence. 
Crystallized intelligence akan terus meningkat seiring bertambahnya pengetahuan dan pengalaman seseorang. Terutama jika dia terus menggunakan pengetahuan dan pengalamannya secara berulang. Pengetahuan dan pengalaman seseorang terkait kondisi lingkungan terekam oleh kemampuan representasi lingkungan di dalam pikirannya. Kemampuan manusia untuk membuat representasi lingkungan pun ditentukan oleh kondisi lingkungannya. "As cognitive, they are presumed to differ from 'true' maps of the environment" (Tversky, 1993, hlm. 14). Sejalan dengan pernyataan tersebut, Hespanha dkk. (2009, hlm. S19) menjelaskan bahwa "we propose that undergraduate educators should focus some effort on helping students achieve higher levels of spatial literacy by designing tools that encourage students to engage in advanced problem-solving in a wide range of social science domains." Berdasarkan pendapat tersebut dapat diambil informasi yang lain, yakni kecerdasan spasial pun dapat digunakan untuk mengkaji masalah sosial dalam sudut pandang spasial. Kepekaan sosial akan berpengaruh terhadap perilaku spasial peserta didik. Untuk mendukung hal tersebut, maka kecerdasan spasial peserta didik harus terus dikembangkan.

Kecerdasan spasial memberikan kemampuan individu dalam menentukan orientasi dan mobilisasi. Kemampuan tersebut dapat direpresentasikan menjadi tiga kemampuan yaitu cognitive maps, cognitive collage, dan spatial mental. Ketiga kemampuan ini merepresentasikan kemampuan manusia untuk menjelajah permukaan bumi dengan cara mentransformasikan berbagai jenis informasi yang didapat dari lingkungan menjadi informasi spasial. Hal ini berdasarkan pada pernyataan Tversky (1993, hlm. 15) yang menyatakan bahwa

...where environments are simple or well-learned, people seem to have quite accurate mental representations of spatial layouts. On close examination, these representations capture the categorical spatial relations among elements coherently, allowing perspective-taking, reorientation, and spatial inferences. In contrast to cognitive maps and cognitive collages, these have been termed spatial mental models.

Mekanisme pengaruh lingkungan sekolah terhadap kecerdasan spasial dijembatani oleh dua faktor, yaitu affordance dan geo-literacy. Esensi dari teori affordance ini dikemukakan oleh Quinnel (2015, hlm. 56) yang menyatakan bahwa "the theory of affordances, which was influenced by Gestalt theory, theorizes that the animal interprets its environment as possibilities of action that are reliant on the physical attributes of the animal and the object." Kata affordance merupakan terminologi yang dibuat oleh James J. Gibson untuk menyatakan kemampuan individu dalam menciptakan peluang tindakan terhadap lingkungan.

Geo-literacy adalah istilah yang diadopsi oleh National Geographic untuk menjelaskan pemahaman manusia tentang cara bumi ini bekerja dalam konteks masyarakat modern yang mengutamakan pola pikir spasial. Pernyataan ini didasarkan dari definisi geo-literacy yang dibuat oleh National Geography Society (2009) yang menyatakan sebagai berikut

Geo-literacy is the ability to reason about Earth systems and interconnections to make far-reaching decisions. Whether we are making decisions about where to live or what precautions to take for natural hazards, we all make decisions that require geo-literacy throughout our lives. This video illustrates what geoliteracy means to individuals and to our global community. 
Geo-literacy merupakan gabungan antara pengetahuan dan keterampilan seseorang untuk menganalisis gejala dan peristiwa yang terjadi di permukaan bumi. Pengetahuan didapatkan dari hasil mempelajari sesuatu sedangkan keterampilan didapatkan dari tindakan atau pengalaman yang dilakukan secara berulang-ulang. Di sini akan didapatkan sebuah benang merah antara geo-literacy dengan kecerdasan spasial sebagai cryztallized intelligence. Benang merah tersebut adalah kecerdasan spasial akan dipengaruhi oleh pengetahuan dan tindakan yang berhubungan dengan ruang yaitu geo-literacy.

\section{METODE PENELITIAN}

Penelitian survey ini dilakukan di sekolah menengah atas negeri di Kota Bandung dan Kabupaten Bandung dengan jumlah sampel sebanyak 264 responden. Instrumen penelitian yang digunakan sebanyak tiga jenis, yaitu (1) instrumen observasi (lingkungan sekolah), (2) instrumen non tes (affordance), (3) instrumen tes (geo-literacy dan kecerdasan spasial). Setiap data hasil pengukuran dianalisis dengan analisis jalur untuk diketahui pengaruh setiap variabel independen terhadap variabel dependen sesuai dengan model yang telah ditentukan.

\section{HASIL DAN PEMBAHASAN Hasil Penelitian}

Data hasil pengukuran lapangan diolah dengan menggunakan software IBM SPSS AMOS 21. Hasil analisis jalur oleh software ditampilkan dalam bentuk model yang sudah dicantumkan hasil ujinya. Adapun hasil uji disajikan dalam bentuk persamaan standardized. Untuk lebih jelasnya dapat dilihat pada gambar 1 .

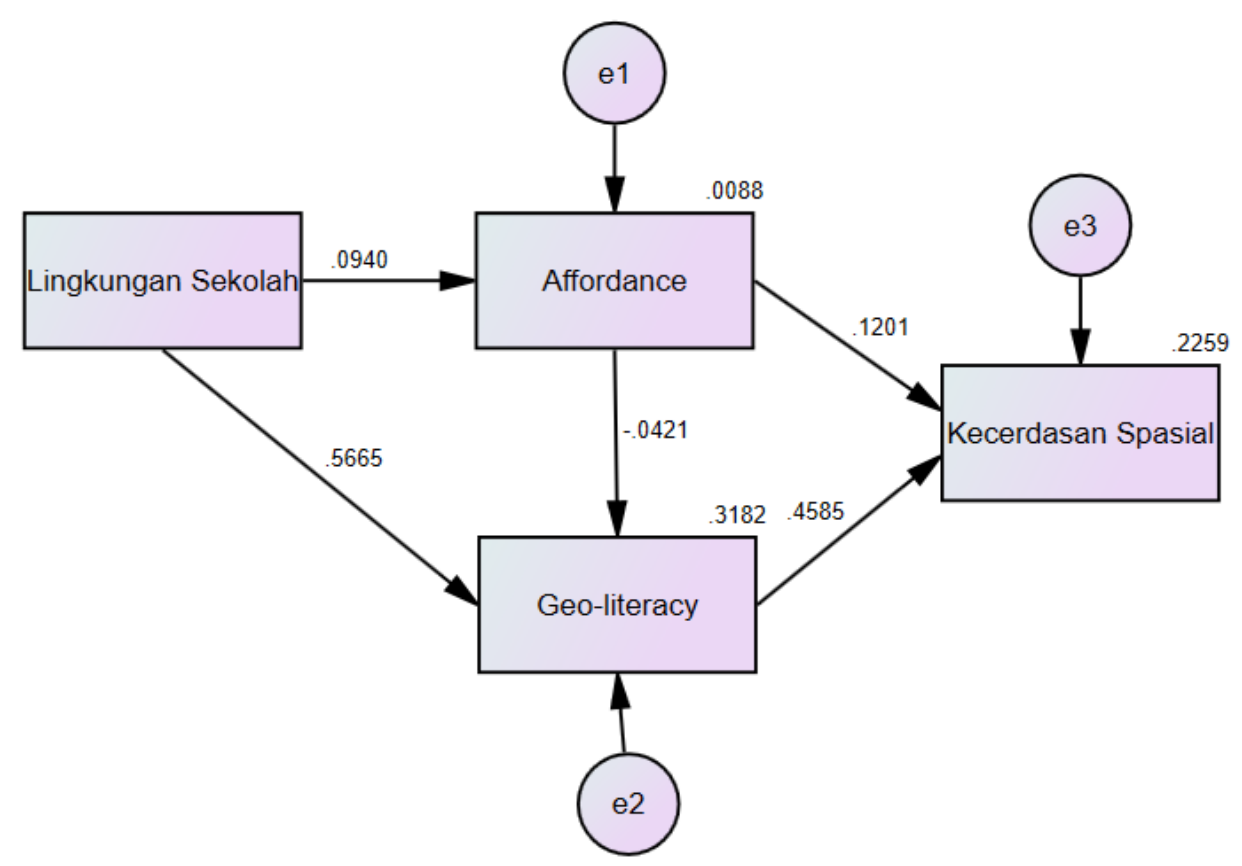

Gambar 1. Full path diagram model penelitian (Standardized)

Gambar 1 merupakan model standardized hasil analisis jalur variabel penelitian. Persamaan regresi standardized digunakan untuk mengetahui kontribusi setiap variabel independen terhadap variabel dependen. Pada gambar 1 dapat dilihat terdapat lima angka untuk masing- masing regression weight (tanda panah), yaitu 0,0940 (W1), 0,5665 (W2), -0,0421 (W3), 0,1201 (W4) dan 0,4585 (W5). Kemudian ada juga angka yang tercantum pada variabel (tanda persegi panjang), yaitu affordance (0,0088), geo-literacy $(0,3182)$, dan kecerdasan spasial $(0,2259)$. 
Angka yang tercantum pada variabel merupakan merupakan nilai squared multiple correlation atau koefisien determinasi multipel $\left(\mathrm{R}^{2}\right)$. Nilai $\mathrm{R}^{2}$ menunjukkan akurasi persamaan yang dihasilkan. Nilai $\mathrm{R}^{2}$ berkisar antara $0-1$. Semakin tinggi nilai $\mathrm{R}^{2}$ maka semakin akurat persamaan yang dihasilkan. Adapun data yang menunjukkan kecocokan model dengan data sampel yang dianalisis adalah Comparative Fit Index atau CFI. Nilai CFI berkisar antara 0 -1 , namun dianjurkan lebih besar dari 0,9. Jika suatu model mendapatkan nilai CFI > 0,9 maka dapat dikatakan bahwa model tersebut adalah baik atau cocok dengan sampel yang diuji. Model penelitian ini memiliki nilai $\mathrm{CFI}=0,879$, sehingga model ini tergolong model yang dapat diterima dan cocok dengan sampel yang diuji.

Dari model standardized yang sudah dijelaskan, maka dapat diturunkan menjadi tiga persamaan regresi untuk setiap variabel. Ada empat variabel yang terlibat dalam penelitian ini, yaitu lingkungan sekolah $(X)$, affordance $\left(\mathrm{Y}_{1}\right)$, geo-literacy $\left(\mathrm{Y}_{2}\right)$, dan kecerdasan spasial $\left(\mathrm{Y}_{3}\right)$. Berikut ini tiga persamaan regresi untuk keempat variabel.

$$
\begin{gathered}
Y_{1}=0,0940 X+e_{1} \ldots(1) \\
Y_{2}=0,5665 X-0,0421 Y_{1}+e_{2} \ldots \\
Y_{3}=0,1201 Y_{1}+0,4585 Y_{2}+e_{3} \ldots(3)
\end{gathered}
$$

Ketiga

persamaan

menggambarkan kontribusi setiap variabel independen terhadap variabel dependen. Kemudian simbol $\mathrm{e}_{1}, \mathrm{e}_{2}$ dan $\mathrm{e}_{3}$ merupakan variabel residual. Variabel residual merupakan variabel lain yang berpengaruh terhadap variabel dependen namun tidak diteliti dalam penelitian. Walaupun setiap variabel sudah diketahui koefisien regresinya, namun hasil tersebut belum menggambarkan besarnya kontribusi setiap variabel secara jelas. Oleh karena itu, setiap koefisien regresi harus dikonversi ke dalam bentuk persen.

Rumus yang digunakan untuk mencari pengaruh variabel independen dalam persen adalah nilai beta dikuadratkan. Kemudian untuk mengetahui pengaruh nilai residual dalam bentuk persen adalah mengurangi nilai $100 \%$ dengan koefisien beta yang dikuadratkan. Secara matematis, rumus tersebut dapat dituliskan sebagai berikut.

Pengaruh Variabel Independen $=\beta^{2} \times 100 \%$ Pengaruh Nilai Residual

$=100 \%-$ pengaruh variabel independen

Hasil dari perhitungan tersebut disajikan dalam bentuk tabel. Untuk lebih jelas, dapat dilihat pada tabel 1. Kemudian hasil pada tabel disajikan dalam bentuk model analisis jalur dalam persen agar mudah dipahami. Model ini dapat dilihat pada gambar 1 .

Tabel 1. Pengaruh Variabel Independen dan Nilai Residual dalam Bentuk Persen

\begin{tabular}{|c|l|c|c|c|c|}
\hline NO & Model & $\boldsymbol{\beta}$ & $\boldsymbol{\beta}^{\mathbf{2}}$ & Pengaruh Variabel Independen & Pengaruh Nilai Residual \\
\hline 1. & Pertama & 0,0940 & 0,008836 & $0,88 \%$ & $99,116 \%$ \\
\hline 2. & Kedua & 0,5665 & 0,320923 & $32,09 \%$ & $67,731 \%$ \\
\hline 3. & & 0,0421 & 0,001772 & $0,17 \%$ & $7,535 \%$ \\
\hline 4. & Ketiga & 0,1201 & 0,014424 & $1,44 \%$ & \multirow{2}{*}{$21,02 \%$} \\
\hline 5. & & 0,4585 & 0,2102223 & & \\
\hline
\end{tabular}




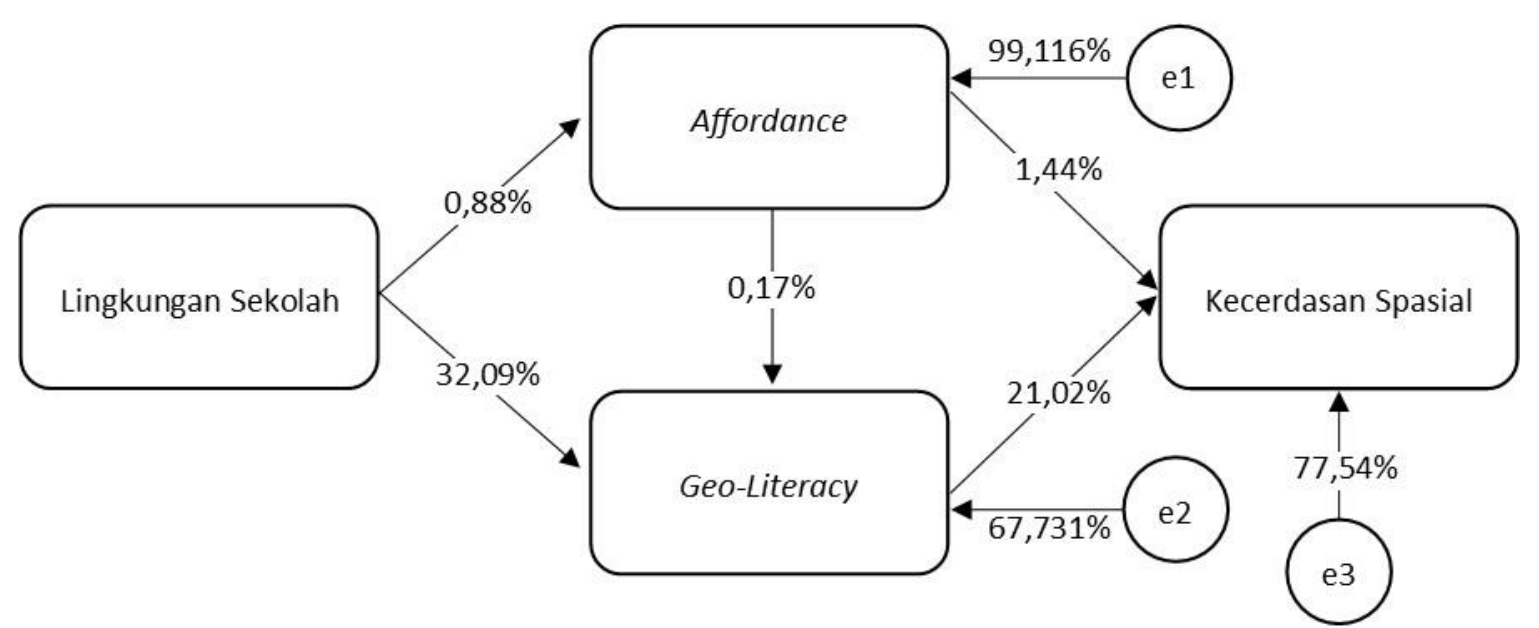

Gambar 2. Full Path Analisis Jalur dengan Residual (Persentase)

Berdasarkan gambar 2 dapat disimpulkan bahwa semua nilai residual memiliki persentase kontribusi yang lebih besar dibanding variabel independen yang diobservasi. Variabel independen dengan kontribusi paling besar adalah lingkungan sekolah terhadap geo-literacy $(32,09 \%)$ dan geo-literacy terhadap kecerdasan spasial $(21,02 \%)$. Sedangkan variabel independen dengan kontribusi paling kecil adalah affordance terhadap geo-literacy $(0,17 \%)$, lingkungan sekolah terhadap affordance $(0,88 \%)$, dan affordance terhadap kecerdasan spasial $(1,44 \%)$. Kesimpulan yang dapat diambil dari hasil penelitian adalah, pengaruh lingkungan sekolah terhadap kecerdasan spasial paling efektif jika melibatkan variabel geoliteracy.

\section{Pembahasan}

Lingkungan sekolah yang berpengaruh terhadap affordance didefinisikan sebagai lingkungan sekolah yang berhubungan dengan perkembangan kecerdasan spasial sekaligus meningkatkan affordance peserta didik. Peneliti menduga bahwa lingkungan sekolah yang sesuai dengan kriteria ini adalah lingkungan sekolah yang memiliki banyak objek visual di sekitarnya, baik dalam bentuk denah sekolah, label kelas, lukisan, foto, majalah dinding dan sebagainya. Semua kriteria tersebut dimasukkan ke dalam instrumen observasi dan diisi sesuai dengan kondisi setiap sekolah yang dijadikan sampel penelitian.

Teori affordance dalam penelitian ini digunakan untuk mengukur keberagaman persepsi terhadap lingkungan yang dimiliki peserta didik di tingkat SMA. Peserta didik di tingkat SMA umumnya berusia 17 tahun hingga 19 tahun. Pada fase ini kemampuan berpikir mereka sudah cukup tinggi sehingga dapat memahami sesuatu yang bersifat kompleks. Tentu hal ini berpengaruh terhadap affordance yang mereka miliki. Selain affordance, interaksi peserta didik dengan warga sekolah yang lain dan objek-objek yang ada di lingkungan sekolah memiliki pengaruh terhadap perilaku mereka.

Peserta didik yang memiliki affordance tinggi dicirikan dengan kemampuan mereka untuk menciptakan berbagai tindakan pada lingkungan tertentu. Kata "menciptakan" merujuk pada kemampuan untuk memikirkan dan menguraikan langkah-langkah dari suatu tindakan, bukan melakukan suatu tindakan sendirian. Misalnya, peserta didik dengan affordance tinggi dapat menata ulang ruang kelasnya menjadi sebuah ruang pameran yang menarik untuk kebutuhan pameran karya seni. Selain ruang pameran, peserta didik pun 
dapat menggunakan objek-objek di dalam kelas untuk mendukung acara pameran karya seni tersebut. Sedangkan peserta didik dengan affordance rendah hanya akan meletakkan lukisan-lukisan atau patung-patung di dalam kelas tanpa memikirkan bagaimana pola penataannya agar menarik.

Berdasarkan hasil analisis jalur yang telah dilakukan, variabel lingkungan sekolah berpengaruh secara signifikan sebesar 0,553 satuan (standardized regression) terhadap variabel geo-literacy. Sedangkah variabel affordance tidak berpengaruh secara signifikan terhadap variabel geo-literacy. Hal ini menandakan bahwa dalam persamaan model kedua hanya variabel lingkungan sekolah yang dapat menjelaskan dan memprediksikan variabel geo-literacy. Variabel affordance tidak berpengaruh terhadap variabel geoliteracy karena variabel affordance dapat berkedudukan sebagai variabel moderasi.

Dalam penelitian ini, kecerdasan spasial peserta didik diukur melalui tiga kemampuan, yakni cognitive map, cognitive collage, dan spatial mental. Cognitive map merupakan kemampuan peserta didik untuk mengingat lokasi dari suatu objek, peristiwa, atau tempat dan menempatkannya dengan lokasi-lokasi lain yang diketahuinya. Peta mental atau cognitive map merupakan kemampuan dasar dalam kecerdasan spasial. Kemudian Purwanto (2001, hlm. 87) memperkuat argumentasi tersebut dengan menyatakan bahwa "peta mental dipandang sebagai persyaratan baik untuk kelangsungan hidup manusia maupun untuk perilaku spasial setiap harinya." Peserta didik dapat bergerak dari satu tempat ke tempat yang lain dengan baik karena kemampuan cognitive map ini. Kecerdasan spasial pun memberikan kemudahan bagi peserta didik untuk memilih lokasi yang tepat untuk memenuhi kebutuhannya. Tentu saja hal tersebut didukung oleh jumlah informasi yang dimilikinya. Misalnya, seorang peserta didik hendak mencari buku-buku untuk melengkapi tugas makalahnya, maka dia akan mencari perpustakaan. Di dalam pikirannya, dia akan memetakan lokasi perpustakaan dan membandingkan dengan lokasinya pada saat itu. Setelah dia mengetahui lokasi relatifnya terhadap perpustakaan, peserta didik tersebut akan mencari rute terdekat untuk mencapai tempat yang hendak dia tuju. Bahkan peserta didik tersebut dapat menganalisis beberapa rute untuk menemukan rute terbaik yang dapat dia tempuh.

Kemampuan kedua dari kecerdasan spasial adalah cognitive collage. Klonari dan Likouri (2015, hlm. 359) menyatakan bahwa "maps not only depict the world statically, because the use of digital technology and Geoinformatics is adapting to the new forms of organization and presentation of spatial data". Hal ini berarti peta tidak hanya menyajikan informasi secara statis, tapi juga dinamis. Kemampuan cognitive map tidak akan berfungsi secara optimal jika tidak diserta dengan informasi yang bersifat dinamis. Cognitive collage merupakan kemampuan yang merepresentasikan lokasi secara aktual dan dinamis, sehingga kemampuan ini digunakan untuk melengkapi kemampuan pertama, yaitu cognitive map. Ketika peserta didik sudah memetakan lokasi-lokasi yang hendak dia tuju dalam pikirannya, maka cognitive collage memberikan gambaran visual mengenai lokasi-lokasi tersebut. Gambaran visual ini didapatkan dari pengalaman yang didapat pada waktu sebelumnya. Kemampuan berpikir spasial pun harus didukung oleh banyak informasi yang diperoleh dari hasil eksplorasi lingkungan di sekitarnya. Setiap informasi yang diterima akan membantu peserta didik untuk menganalisis berbagai fenomena secara spasial. Peserta didik yang memiliki pengalaman eksplorasi yang banyak akan memiliki kemampuan cognitive collage 
yang lebih tinggi dibanding peserta didik yang pengalaman eksplorasinya rendah.

$$
\text { Kemampuan ketiga dari }
$$

kecerdasan spasial adalah spatial mental. Spatial mental merupakan kemampuan tertinggi dalam kecerdasan spasial. Spatial mental ditunjukkan dengan kemampuan pikiran untuk merepresentasikan proses yang terjadi di lingkungan di dalam pikiran. Fungsi dari kemampuan ini adalah menjelaskan penyebab dari suatu fenomena dan memprediksikan dampak dari suatu fenomena. Semakin tinggi kemampuan seseorang dalam aspek spatial mental ini maka akan semakin tinggi kemampuan orang tersebut dalam memprediksikan fenomena dalam ruang.

Variabel affordance dan variabel geoliteracy memiliki kontribusi yang berbeda dalam mempengaruhi kecerdasan spasial. Lebih tepatnya variabel geo-literacy memiliki kontribusi yang lebih besar dibanding variabel affordance dalam menentukan tingkat kecerdasan spasial peserta didik. Geo-literacy merupakan konsep yang melibatkan kecerdasan spasial dalam usaha pengambilan keputusan yang bersifat komprehensif. Affordance merupakan persepsi terhadap lingkungan yang menentukan tindakan seseorang dalam konteks spasial. Ketiga variabel ini memiliki persamaan yaitu menjelaskan konsep yang berkaitan dalam konteks spasial. Kemudian hubungan tersebut diperkuat dengan hasil analisis jalur yang menunjukkan kedua variabel ini berpengaruh positif terhadap kecerdasan spasial. Selain itu, penggunaan komputer dalam mata pelajaran Geografi pun dapat menjadi faktor lain yang mempengaruhi kecerdasan spasial. "Computers have become an increasingly important and popular platform for the administration of practice tests within institutions of higher education" (Wilson dkk. 2011, hlm. 1493).

Hasil dari penelitian ini menunjukkan bahwa penataan lingkungan sekolah dapat direncanakan untuk mengembangkan kecerdasan spasial peserta didik melalui peningkatan affordance dan geo-literacy. Setiap objek seperti poster, majalah dinding, denah sekolah hingga petunjuk arah memiliki perannya tersendiri dalam meningkatkan variabel-variabel tersebut. Lingkungan sekolah merupakan stimulus penting untuk mengarahkan perilaku spasial peserta didik menjadi lebih efektif dan efisien. Untuk meningkatkan affordance, lingkungan sekolah harus dirancang dengan berbagai informasi lokasi yang lengkap seperti denah, petunjuk arah, hingga rambu-rambu sekolah. Hal ini dimaksudkan agar peserta didik terbiasa untuk berpikir dengan menggunakan gambar. Gambar memiliki pengaruh besar dalam peningkatan affordance karena gambar memiliki kemampuan untuk menyampaikan banyak makna dibanding dengan informasi berupa tulisan. Gambar dapat membuka persepsi baru terhadap lingkungan. Peserta didik akan banyak menemukan alternatifalternatif baru untuk bergerak dalam ruang. Setidaknya mereka akan mampu mencari jalan yang berbeda untuk mencapai suatu ruangan atau lokasi. Kesimpulannya, objek-objek gambar di lingkungan sekolah akan meningkatkan kemampuan peserta didik dalam mencari alternatif tindakan terhadap lingkungan.

Geo-literacy sebagai variabel kedua yang dipengaruhi oleh lingkungan memiliki pengaruh yang lebih besar terhadap kecerdasan spasial dibanding affordance. Tindak lanjut yang dapat dilakukan terkait hal ini adalah menggunakan lingkungan sebagai sarana untuk menyampaikan isu-isu mengenai lingkungan dan kebumian. Langkah tersebut diprediksi dapat meningkatkan kecerdasan spasial peserta didik, karena isu-isu tersebut akan menstimulasi peserta didik untuk berpikir secara lateral (bercabang). Jika affordance mendukung kecerdasan spasial dari aspek persepsi, maka geo-literacy mendukung kecerdasan 
spasial dari aspek pengetahuan geografi. Pengetahuan geografi dapat ditransfer dari lingkungan sekolah kepada peserta didik melalui penggunaan media yang tepat. Jika ingin mendapatkan hasil yang optimal, media yang digunakan tentu saja harus media audio visual seperti LCD TV dengan kualitas speaker yang baik. Namun jika lingkungan sekolah memiliki keterbatasan untuk menyediakan hal tersebut, maka media yang digunakan dapat berupa media cetak atau media model. Hal yang menjadi fokus utamanya bukan kecanggihan media, melainkan kelengkapan informasi yang disampaikan oleh media. Walaupun media yang digunakan hanya media cetak, namun jika informasi yang disampaikannya lengkap dan mudah dipahami peserta didik, secara perlahan media tersebut akan mempengaruhi pola pikir peserta didik.

Lingkungan sekolah sebagai stimulus yang berpengaruh terhadap persepsi dan pengetahuan spasial telah teruji secara statistik berdampak pada kecerdasan spasial. Konsep kecerdasan spasial dalam pembelajaran Geografi tidak memiliki orientasi yang sama dengan konsep kecerdasan spasial yang digagas oleh Howard Gardner. Gardner memposisikan kecerdasan spasial sebagai potensi individu untuk membayangkan berbagai bentuk (baik dua dimensi atau tiga dimensi) serta menentukan desain terbaik untuk suatu objek. Namun dalam pembelajaran Geografi, kecerdasan spasial diperuntukkan untuk membentuk perilaku spasial peserta didik. Perilaku spasial yang ideal dari sudut pandang pembelajaran Geografi adalah perilaku yang dilakukan berdasarkan pertimbangan matang atas berbagai informasi spasial yang dimiliki. Tentu saja ini adalah hal yang kompleks, namun bukan berarti tidak dapat dikembangkan. Kemajuan zaman menuntut manusia untuk berpikir lebih kompleks dan menyeluruh. Pola pikir linier (satu arah) tidak akan mampu mengatasi permasalahan yang terjadi di zaman modern. Sedangkan pola pikir lateral (bercabang) akan mendukung pemecahan berbagai masalah kontemporer. Pola pikir lateral salah satunya dapat dilakukan melalui pola pikir spasial yang didasari oleh kecerdasan spasial. Maka tidak heran apabila National Geographic Society menyebutkan bahwa pola pikir spasial adalah pola pikir masyarakat modern yang memiliki banyak masalah kompleks yang harus dihadapi. Kecerdasan spasial akan mendasari kemampuan berpikir secara spasial yang pada akhirnya akan terwujud dalam perilaku spasial. Hal ini dapat dicontohkan dengan seorang wisatawan dari Indonesia yang hendak berwisata ke Jepang pada bulan Desember. Wisatawan tersebut akan berpikir tentang musim yang sedang berlangsung di Jepang. Kemudian dia akan menentukan barang apa saja yang akan dia bawa untuk berwisata. Pada bulan Desember, Jepang sedang mengalami musim dingin, maka wisatawan tersebut akan membawa baju hangat serta barang lain yang mampu mengantisipasi rasa dingin. Masih banyak contoh dari aplikasi perilaku spasial yang bermanfaat dalam kehidupan sehari-hari pada masyarakat modern. Karena itu, konsep kecerdasan spasial dalam pembelajaran Geografi perlu terus dikembangkan agar melahirkan konsep yang valid dan baku. Hal ini dimaksudkan agar setiap guru Geografi di Indonesia memiliki persepsi yang sama untuk mengembangkan kecerdasan spasial peserta didik di sekolahnya masing-masing.

\section{SIMPULAN}

Berdasarkan uraian dari pendahuluan hingga pembahasan, maka dapat disimpulkan tiga hal utama yang menjadi hasil penelitian. Kesimpulan tersebut antara lain sebagai berikut.

1. Lingkungan sekolah berpengaruh terhadap affordance sebesar 0,88\%. 
Namun lingkungan sekolah tidak berpengaruh secara signifikan terhadap affordance peserta didik.

2. Lingkungan sekolah secara signifikan berpengaruh positif terhadap geoliteracy dan affordance tidak berpengaruh secara signifikan terhadap geo-literacy. Adapun besarnya pengaruh lingkungan sekolah terhadap geo-literacy adalah $32,09 \%$ dan pengaruh affordance terhadap geo-literacy adalah $0,18 \%$.

3. Geo-literacy dan affordance secara signifikan berpengaruh positif terhadap kecerdasan spasial. Pengaruh geo-literacy terhadap kecerdasan spasial adalah $21,02 \%$ dan pengaruh affordance terhadap kecerdasan spasial adalah 1,44\%.

\section{REKOMENDASI}

Setelah menyimak artikel ini dari pendahuluan hingga simpulan, maka penulis mengajukan beberapa rekomendasi terkait tindak lanjut dari hasil penelitian. Adapun rekomendasi yang diajukan adalah sebagai berikut.

1. Penekanan konsep kecerdasan spasial pada penelitian ini adalah cognitive map, cognitive collage dan spatial mental. Karena itu, peneliti merekomendasikan hasil penelitian dapat dijadikan acuan bagi peneliti selanjutnya. Hal ini dimaksudkan agar konsep kecerdasan spasial untuk pembelajaran Geografi dapat tergali secara tepat.

2. Usaha peningkatan kecerdasan spasial dapat dilakukan melalui peningkatan geo-literacy peserta didik. Hal tersebut dapat dilakukan dengan berbagai cara, misalnya menjelaskan contoh isu lingkungan yang aktual dan menganalisisnya dari sudut pandang Geografi.

\section{DAFTAR PUSTAKA}

Hespanha, Stacy Rebich, Goodchild, Fiona dan Janelle, Donald G. (2009). Spatial Thinking and Technologies in the Undergraduate Social Science Classroom. Journal of Geography in Higher Education, Vol. 33, Supplement 1, S17-S27, 2009. ISSN 0309-8265 tersedia di http:/ / www.tandfonline.com/d oi/pdf/10.1080/030982609030339 $\underline{98}$

Klonari, A dan Likouri, A. 2015. The Relation of Multiple Intelligences and Spatial Perception with Performance in Geography Education. Journal for Geographic Information and Science. Published online June 2015. ISSN 2308-1708. DOI: $10.1553 /$

giscience2015. (C) 2011 Elsevier Ltd. Tersedia di http:/ /hw.oeaw.ac.at/ ?arp=0x003 $\underline{24 a 5 d}$

National Geographic Society. (2009). Geography For Life, 2 ${ }^{\text {nd }}$ Edition National Geography Standards. Geography Education National Implementation Project.

Newcombe, N., Huttenlocher, J., Drummey, A.B., Wiley J.G. (1998). The Development of Spatial Location Coding: Place Learning and Dead Reckoning in The Second and Third Years. Cognitive Development, 13, page 185-200. ISSN 0885-2014 tersedia di http://doi.apa.org/ journals/amp/51/2/77.pdf

Oktaviana, I. (2015). Pengaruh Lingkungan Sekolah terhadap Motivasi Belajar Siswa Kelas $V$ Sekolah Dasar di Daerah Binaan I Kecamatan Limpung Kabupaten Batang. Skripsi pada Jurusan Pendidikan Guru Sekolah Dasar Universitas Negeri 
Semarang: Semarang. Tersedia di http:/ /lib.unnes.ac.id/21074/1/14 01411503-s.pdf

Quinnel, K. 2015. Student Perception of Informal Learning Spaces Using Gibson's Theory of Affordances. A Dissertation Submitted to the Faculty in the Educational Leadership Program of Tift College of Education at Mercer University. Published by ProQuest LLC (2015). ProQuest Number: 3664537. Tersedia di http://eresources.perpusnas.go.id/ library.php?id=00001

Sudikno, I dan Aminah, Y. (2014). Pengaruh Lingkungan Keluarga, Lingkungan Sekolah, Disiplin Belajar dan Motivasi Belajar terhadap Prestasi Belajar Ekonomi Siswa SMA Kelas XI IPS SMA PGRI 1 Taman Pemalang. Economic Education Analysis Journal Vol 3 Nomor 1 tahun 2014. ISSN 2252-6544 tersedia di http://journal. unnes.ac.id/artikel_sju/eeaj/4131
Tversky, B. (1993). Cognitive Maps, Cognitive Collages, and Spatial Mental Models. In Frank, A.U. and Campari, I. (Eds.) Spatial Information Theory: A Theoretical Basis for GIS, Proceedings COSIT '93. Lecture Notes in Computer Science, 716, pp.14-24, Springer: Berlin. Tersedia di https:// www.tc.columbia.edu/ faculty/bt2158/faculty-profile/ files/emaps,cognitivecollages, ands patialmentalmodels.PDF

Wilson, K., Boyd, C., Chen, L. dan Jamal, S. (2011). Improving Student Performance in A First-Year Geography Course: Examining The Importance of Computer-Assisted Formative Assessment. Journal of Computers and Education 57 (2011) page 1493-1500. ISSN 03601315.

DOI: 10.1016/j.compedu.2011.02.011. (C) 2011 Elsevier Ltd. Tersedia di http://www.sciencedirect.com/sc ience/article/pii/S03601315110004 $\underline{92}$ 